\title{
PBI-4050 Reduces Stellate Cell Activation and Liver Fibrosis through Modulation of Intracellular ATP Levels and the Liver Kinase B1/AMP-Activated Protein Kinase/Mammalian Target of Rapamycin Pathways
}

\author{
Brigitte Grouix, Francois Sarra-Bournet, Martin Leduc, Jean-Christophe Simard, Kathy Hince, \\ Lilianne Geerts, Alexandra Blais, Liette Gervais, Alexandre Laverdure, Alexandra Felton, \\ Jonathan Richard, Jugurtha Ouboudinar, William Gagnon, François A. Leblond, \\ Pierre Laurin, and (1) Lyne Gagnon
}

Prometic BioSciences Inc., Laval, Québec, Canada

Received April 17, 2018; accepted July 12, 2018

\begin{abstract}
Hepatic fibrosis is a major cause of morbidity and mortality for which there is currently no effective therapy. We previously showed that 2-(3-pentylphenyl)acetic acid (PBI-4050) is a dual G protein-coupled receptor GPR40 agonist/GPR84 antagonist that exerts antifibrotic, anti-inflammatory, and antiproliferative action. We evaluated PBI-4050 for the treatment of liver fibrosis in vivo and elucidated its mechanism of action on human hepatic stellate cells (HSCs). The antifibrotic effect of PBI-4050 was evaluated in carbon tetrachloride $\left(\mathrm{CCl}_{4}\right)$ - and bile duct ligation-induced liver fibrosis rodent models. Treatment with $\mathrm{PBI}-4050$ suppressed $\mathrm{CCl}_{4}$-induced serum aspartate aminotransferase levels, inflammatory marker nitric oxide synthase, epithelial to mesenchymal transition transcription factor Snail, and multiple profibrotic factors. PBI-4050 also decreased GPR84 mRNA expression in $\mathrm{CCl}_{4}$-induced injury, while restoring peroxisome proliferator-activated receptor $\gamma($ PPAR $\gamma$ ) to the control
\end{abstract}

level. Collagen deposition and $\alpha$-smooth muscle actin ( $\alpha$-SMA) protein levels were also attenuated by $\mathrm{PBI}-4050$ treatment in the bile duct ligation rat model. Transforming growth factor- $\beta$-activated primary HSCs were used to examine the effect of PBI-4050 and its mechanism of action in vitro. PBI-4050 inhibited HSC proliferation by arresting cells in the G0/G1 cycle phase. Subsequent analysis demonstrated that $\mathrm{PBI}-4050$ signals through a reduction of intracellular ATP levels, activation of liver kinase B1 (LKB1) and AMP-activated protein kinase (AMPK), and blockade of mammalian target of rapamycin (mTOR), resulting in reduced protein and mRNA levels of $\alpha$-SMA and connective tissue growth factor and restored PPAR $\gamma$ mRNA expression. Our findings suggest that PBI-4050 may exert antifibrotic activity in the liver through a novel mechanism of action involving modulation of intracellular ATP levels and the LKB1/AMPK/mTOR pathway in stellate cells, and $\mathrm{PBI}-4050$ may be a promising agent for treating liver fibrosis.

\section{Introduction}

Hepatic fibrosis is a major cause of morbidity and mortality worldwide. Fibrosis, a wound-healing response to chronic liver injury, is characterized by excessive overproduction and deposition of extracellular matrix (ECM) (Friedman, 2008; Schuppan and Kim, 2013). During fibrogenesis, human hepatic stellate cells (HSCs) are activated and transdifferentiate into proliferative, myofibroblast-like cells, which are the major cell type responsible for ECM synthesis and

This work was supported by Prometic BioSciences Inc. The authors are employees of and hold shares in Prometic Life Sciences Inc.

https://doi.org/10.1124/jpet.118.250068.

S This article has supplemental material available at jpet.aspetjournals.org. accumulation (Bataller and Brenner, 2005). Transformation of HSCs to myofibroblasts is characterized by several phenotypic changes, such as overexpression of $\alpha$-smooth muscle actin ( $\alpha$-SMA); secretion of profibrotic mediators, including connective tissue growth factor (CTGF) (Friedman, 2000); loss of expression of peroxisome proliferator-activated receptor $\gamma$ (PPAR $\gamma$ ), a transcription factor essential for HSC differentiation (Kweon et al., 2016); and secretion of type I collagen (Henderson and Iredale, 2007). Therefore, modulating HSC activation may be a potential antifibrosis therapy.

Recent studies have reported a close relationship between hepatic fibrosis and AMP-activated protein kinase (AMPK), a cellular energy sensor (Liang et al., 2017). Lim et al. (2012) found that AMPK activation inhibits transforming growth

ABBREVIATIONS: $\alpha$-SMA, $\alpha$-smooth muscle actin; AMPK, AMP-activated protein kinase; AST, serum aspartate aminotransferase; BDL, bile duct ligation; $\mathrm{CCl}_{4}$, carbon tetrachloride; CTGF, connective tissue growth factor; ECM, extracellular matrix; FBS, fetal bovine serum; GAPDH, glyceraldehyde 3-phosphate dehydrogenase; GPR, G protein-coupled receptor; HSC, human hepatic stellate cell; iNOS, inducible nitric oxide synthase; LKB1, liver kinase B1; MMP, matrix metalloproteinase; PBI-4050, 2-(3-pentylphenyl)acetic acid; PDGF-BB, platelet-derived growth factor $\mathrm{BB}$; PPAR $\gamma$, peroxisome proliferator-activated receptor $\gamma$; qPCR, quantitative polymerase chain reaction; TGF, transforming growth factor; TIMP, tissue inhibitor of metalloproteinase. 
factor (TGF)- $\beta$-mediated activation of cultured HSCs, and AMPK activation has thus been a target of various antifibrosis therapies. Direct AMPK activator 5-aminoimidazole4-carboxamide ribonucleotide and indirect AMPK activators such as metformin, berberine, or cucurbitacin $\mathrm{E}$ are reported to have antifibrotic activity in both activated HSCs and animal models of hepatic fibrosis, such as the carbon tetrachloride $\left(\mathrm{CCl}_{4}\right)$-induced liver injury or bile duct ligation (BDL) rodent models (Leclerc et al., 2010; Kumar et al., 2014; Li et al., 2014; Tripathi et al., 2015; Wang et al., 2016; Wu et al., 2016).

We previously showed that 2-(3-pentylphenyl)acetic acid (PBI-4050) is a synthetic agonist of G protein-coupled receptor GPR40 $\left(\mathrm{EC}_{50}\right.$ of 288 and $30 \mu \mathrm{M}$ for activation of $\mathrm{GPR} 40 / \mathrm{G} \alpha_{\mathrm{q}}$ and $\mathrm{G} \alpha_{\mathrm{i} 2}$, respectively) and an antagonist of $\mathrm{GPR} 84$ ( $\mathrm{IC}_{50}$ of 398 and $209 \mu \mathrm{M}$ for inhibition of sodium decanoate- and embelin-induced activation of GPR84/G $\alpha_{\mathrm{i} 2}$, respectively) (Gagnon et al., 2018). GPR40 and GPR84 are both fatty-acid binding receptors; GPR40 is activated by both medium- and long-chain fatty acids (Briscoe et al., 2003), whereas GPR84 binds only to mediumchain fatty acids (Wang et al., 2006). We recently reported that GPR40 knockout mice are more prone to renal injury-induced fibrosis, whereas GPR84 knockout mice are protected; in addition, PBI-4050 has antifibrotic activity in various animal models of tissue fibrosis as well as in fibroblast and epithelial cells (Gagnon et al., 2018). Moreover, PBI-4050 inhibits TGF- $\beta$-induced activation of normal human dermal fibroblasts to profibrotic myofibroblasts, as demonstrated by abrogation of $\alpha$-SMA, CTGF, and collagen I expression.

Based on PBI-4050 antifibrotic activity reported previously, we hypothesized that PBI-4050 may have a protective effect on hepatic fibrosis. In this study, the antifibrotic activity of PBI-4050 was evaluated in a $\mathrm{CCl}_{4}$-induced liver injury animal model, which is extensively used in experimental studies showing many shared characteristics with human fibrosis (Weiler-Normann et al., 2007). We also confirmed PBI-4050 antifibrotic activity in a BDL rat model of hepatic fibrosis (Biecker et al., 2005). Furthermore, we uncovered a novel mechanism of action of PBI-4050 in activated human HSCs involving modulation of intracellular ATP levels and the liver kinase B1 (LKB1)/AMPK/mammalian target of rapamycin (mTOR) pathway.

\section{Materials and Methods}

Reagents. $\mathrm{CCl}_{4}$ was obtained from Sigma-Aldrich (St. Louis, MO). HSCs and SteCM medium were obtained from ScienCell (Carlsbad, $\mathrm{CA}$ ). The Pierce Coomassie protein assay kit was purchased from BioRad (Hercules, CA). The human CTGF enzyme-linked immunosorbent assay kit was from Origene (Rockville, MD). PBI-4050 was synthesized as previously described (Gagnon et al., 2018).

Cell Culture. HSCs were cultured in SteCM medium with $2 \%$ fetal bovine serum (FBS) plus stellate cell growth supplement and penicillin/streptomycin solution. Cells were starved for 4 hours in medium with $0.4 \%$ FBS and treated with or without $10 \mathrm{ng} / \mathrm{ml}$ recombinant human TGF- $\beta 1$ (BioLegend, San Diego, CA), $10 \mathrm{ng} / \mathrm{ml}$ platelet-derived growth factor BB (PDGF-BB) (R\&D Systems, Minneapolis, MN), and different concentrations of PBI-4050 for 24 hours. Cells were then processed for quantitative polymerase chain reaction (qPCR) and Western blot analysis, and the supernatants were collected for the CTGF enzyme-linked immunosorbent assay.

Animal Studies. All animal studies were reviewed and approved by the Institut National de la Recherche Scientifique-Institut Armand Frappier Animal Care and Ethics Committee.
$\mathbf{C C l}_{4}$-Induced Liver Fibrosis. Liver fibrosis was induced in 6-week-old male C57BL/6 mice (Charles River Laboratories, Wilmington, MA) by intraperitoneal administration (twice a week for 58 days) of $2 \mathrm{~mL} / \mathrm{kg} \mathrm{CCl} 4$ (10\% in olive oil). Mice were randomly divided into four groups. The sham group was injected with an equal volume of olive oil intraperitoneally and an equal volume of distilled water was administered orally. The $\mathrm{CCl}_{4}$ group was injected intraperitoneally with $\mathrm{CCl}_{4}$ and administered an equal volume of vehicle (distilled water) instead of PBI-4050. PBI-4050 (at either 100 or $200 \mathrm{mg} / \mathrm{kg}$ ) was administered orally to $\mathrm{CCl}_{4}$-treated mice from days 1 to 58 . Mice were sacrificed at day 59. Livers were collected to evaluate fibrosis, and blood samples were obtained for the liver enzyme assay.

BDL-Induced Fibrosis. Cholestasis and resulting inflammatory liver disease were induced by a double ligation of the common bile duct (BDL) of male Wistar rats by abdominal laparotomy under isoflurane anesthesia. Silk sutures were tied around the isolated BDL at the cranial and caudal ends and the BDL was transected between the ligatures. Animals were kept under normal housing conditions for up to 8 weeks.

Liver Enzyme Assay. The EnzyChrome Aspartate Transaminase Assay kit (Bioassay Systems, Hayward, CA) was used to determine serum aspartate transaminase (AST) activity at the time of sacrifice.

Western Blot Analysis. Total proteins were extracted from liver tissue and HSCs with lysis buffer. Twenty micrograms of protein was separated by standard SDS-PAGE techniques and immunoblotted with the following antibodies: rabbit anti-AMPK $\alpha$ (1:1000), rabbit anti-phospho-AMPK Thr172 (1:1000), rabbit anti-LKB1 (1:1000), rabbit anti-phospho-LKB1 Ser428 (1:1000), rabbit anti-mTOR (1:1000), rabbit anti-phospho-mTOR Ser2448 (1:1000), and goat anti-rabbit secondary antibody (1:1000) (all from Cell Signaling Technology, Danvers, MA). Rabbit anti- $\alpha$-SMA antibody (1:200) was from Abcam (Cambridge, UK), and anti-glyceraldehyde 3-phosphate dehydrogenase (GAPDH) (1:1000) was from Santa Cruz Biotechnology (Dallas, TX). Chemiluminescence was revealed with a ChemiDoc MP imaging system (Bio-Rad), and densitometric analyses of Western blots were performed using ImageLab software (version 5.2.1; Bio-Rad). Phospho-AMPK, phospho-LKB1, and phospho-mTOR signals were normalized to their respective total proteins and $\alpha$-SMA was normalized to GAPDH or on total amount of loaded protein (MemCode protein stain kit; Fisher Scientific, Waltham, MA).

Cell Cycle. HSCs were treated for 24 hours in complete medium and then harvested and fixed in ice-cold $70 \%$ ethanol for 30 minutes at $4^{\circ} \mathrm{C}$. HSCs were washed twice in phosphate-buffered saline, centrifuged, and resuspended in Krishan buffer containing $0.1 \%$ sodium citrate, $50 \mu \mathrm{g} / \mathrm{ml}$ RNase A, $50 \mu \mathrm{g} / \mathrm{ml}$ propidium iodide, and $0.2 \%$ NP-40. HSCs were incubated for 60 minutes and the cell cycle was analyzed on a FACSCalibur flow cytometer (BD Biosciences, Franklin Lakes, NJ). Results were analyzed using Flowing software (version 2.5.1; Flowing Software, Turku Centre for Biotechnology, Finland).

Cell Proliferation. HSCs were seeded in complete medium in two separate 96 -well plates at a density of $4 \times 10^{3}$ cells/well for attachment overnight. Resazurin (Sigma) was added to the control plate (time 0) and fluorescence was read 4 hours later at $535 \mathrm{~nm}$ (excitation)/595 nm (emission) with a gain of 80. HSCs in the other plate were treated with or without TGF- $\beta 1$ or PDGF-BB and PBI- 4050 for 20 hours before the addition of resazurin. Four hours later, fluorescence was read at $535 \mathrm{~nm}$ (excitation)/595 nm (emission) with a gain of 80 . Results were analyzed and expressed as a percentage of time 0 .

Intracellular ATP Measurement. We plated $1 \times 10^{6} \mathrm{HSCs}$ in a 100-mm culture dish for attachment overnight. Cells were starved for 4 hours in medium with $0.4 \%$ FBS and treated with or without recombinant human TGF- $\beta 1$ and PBI- 4050 for 24 hours. An ATP colorimetric/fluorometric assay (BioVision, Milpitas, CA) was performed per the manufacturer's recommendations, using $5 \times 10^{5}$ cells.

Real-Time qPCR. RNA was extracted from cultured HSCs and homogenized liver tissue using TRIzol reagent (Fisher Scientific) and treated with TURBO DNA-Free DNase (Fisher Scientific) per the manufacturer's instructions. Extracted RNA was converted to cDNA using GoScript Reverse Transcriptase (Promega, Madison, WI) with 
500-1000 ng starting material per reaction. qPCR was performed on an $\mathrm{AB}-7900 \mathrm{HT}$ real-time cycler using TaqMan gene expression assays (Life Technologies, Carlsbad, CA). qPCR data were analyzed using the $\Delta \Delta$ threshold cycle method, with GAPDH or hypoxanthine phosphoribosyltransferase 1 as normalization controls for $\mathrm{CCl}_{4}$ and $\mathrm{HSCs}$, respectively.

Hydroxyproline Determination. One-hundred milligrams of tissue was homogenized in $1 \mathrm{ml}$ distilled water. We transferred $500 \mu \mathrm{l}$ (50 mg tissue) to a pressure-tight vial with a polytetrafluoroethylene-lined cap; $500 \mu \mathrm{l}$ concentrated hydrochloric acid (12 M) was added and tissues were hydrolyzed at $120^{\circ} \mathrm{C}$ overnight. Then $50 \mu \mathrm{l}$ supernatant of each sample was transferred to a 96 -well plate and evaporated to dryness in a $60^{\circ} \mathrm{C}$ oven. Samples were oxidized in $1.4 \%$ chloramine $\mathrm{T}$ solution for 15 minutes at room temperature, after which $100 \mu$ l Ehrlich's solution was added. After 60 -minute incubation at $60^{\circ} \mathrm{C}$, the optical density was read at $560 \mathrm{~nm}$.

Histologic Image Analysis. Liver injury was assessed in a blinded manner. Paraffin slides were deparaffinized, rehydrated, and stained with Masson's trichrome or Picrosirius red. Based on the distinctive density and color of staining in digital images, the area of collagen in the tissue was quantified using Image-Pro Premier 9.1 software (Media Cybernetics, Rockville, MD). Sections from at least four regions of each organ were analyzed, and the average was used as data from one animal sample.

Statistical Analysis. Data are expressed as the mean \pm S.E.M. for each treatment compared with the control. Statistical analysis was performed using one-way analysis of variance with the Dunnett post-test for multiple comparisons. All data were analyzed using GraphPad Prism software (version 7 for Windows; GraphPad Inc., San Diego, CA).

\section{Results}

PBI-4050 Decreases Collagen Deposition in the Liver and AST Serum Levels in Mice With $\mathrm{CCl}_{4}$-Induced Injury. To evaluate the degree of liver fibrosis in mice with
$\mathrm{CCl}_{4}$-induced injury, collagen in liver tissue was determined by Masson's trichrome staining (Fig. 1, A and B). Whereas $\mathrm{CCl}_{4}$ induced collagen accumulation (blue staining) compared with the sham group, PBI-4050 significantly decreased the area of collagen in the liver. These results were confirmed by quantification of hydroxyproline levels (Fig. 1C) and collagen I gene expression (Fig. 1D) in liver tissues, in which PBI-4050 remarkably protected against $\mathrm{CCl}_{4}$-induced collagen accumulation. Moreover, $\mathrm{CCl}_{4}$ administration resulted in an increased level of AST (Fig. 1E), indicative of liver damage. Treatment with $200 \mathrm{mg} / \mathrm{kg}$ PBI-4050 completely prevented the increase of this enzyme in mice compared with the $\mathrm{CCl}_{4}$ group.

PBI-4050 Attenuates $\mathrm{CCl}_{4}$-Induced $\alpha$-SMA Activation in Mice. Previous studies have shown that elevated expression of $\alpha$-SMA is a marker of activated HSCs (Weiler-Normann et al., 2007) and is upregulated by $\mathrm{CCl}_{4}$ treatment (Fan et al., 2017). Indeed, $\alpha$-SMA staining was strongly increased in $\mathrm{CCl}_{4}$-treated mice compared with the sham group, whereas it was markedly reduced in the liver of PBI-4050-treated mice (Fig. 2A). Protein levels of $\alpha$-SMA in liver tissues were also analyzed by Western blot and corroborated that PBI-4050 treatment significantly decreased $\alpha$-SMA compared with $\mathrm{CCl}_{4}$ control mice (Fig. 2B). Moreover, PBI-4050 treatment also decreased expression of the $\alpha$-SMA gene compared with $\mathrm{CCl}_{4}$-treated mice, as shown in Fig. 2C.

PBI-4050 Regulates Gene Expression of Fibrosis/ Inflammation Markers in the Liver of $\mathrm{CCl}_{4}$-Treated Mice. We next investigated the changes in mRNA levels of fibrotic/matrix remodeling markers matrix metalloproteinase (MMP)-2, tissue inhibitor of metalloproteinase (TIMP)-1, and Snail1. A marked elevation of MMP-2, TIMP-1, and Snail1 mRNA levels was observed in $\mathrm{CCl}_{4}$-treated mice and PBI-4050 suppressed the expression of these genes to the level of sham
A
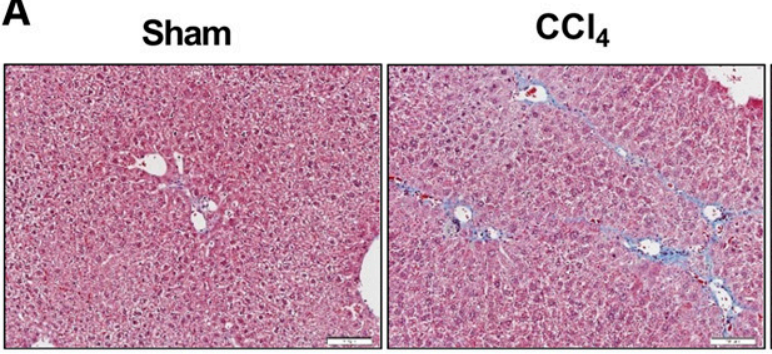

$\mathrm{CCl}_{4}$

$\mathrm{CCl} 4+\mathrm{PBI}-4050$

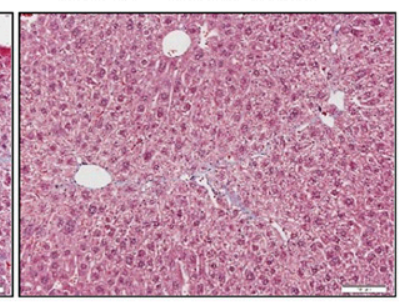

D

C

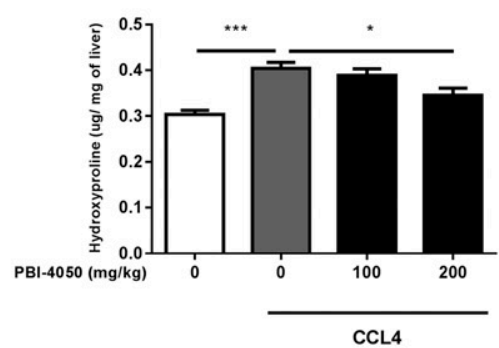

\section{D}

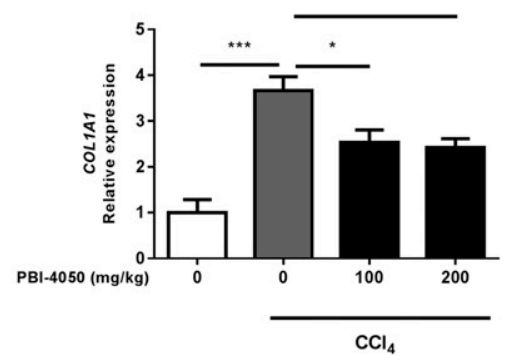

B

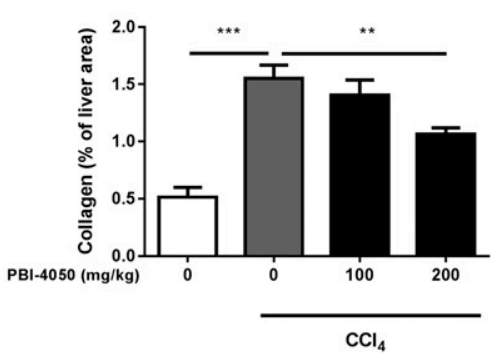

E

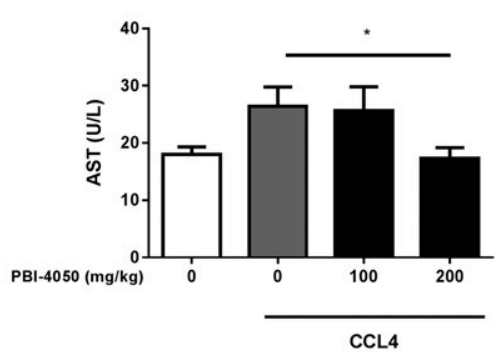

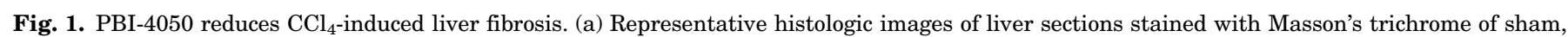

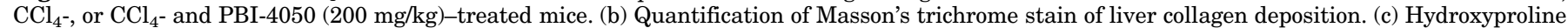

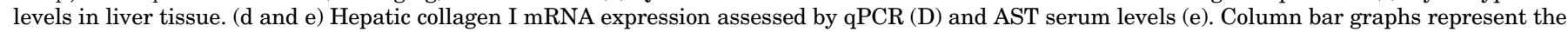

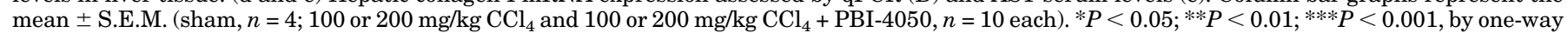
analysis of variance. Scale bar, $100 \mu \mathrm{m}$. 
A

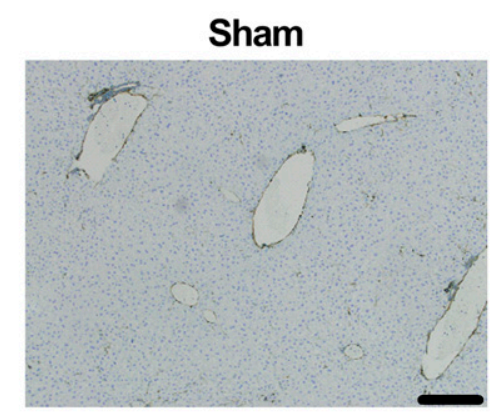

Sham

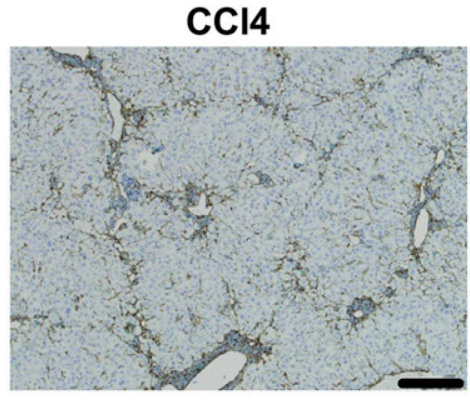

B

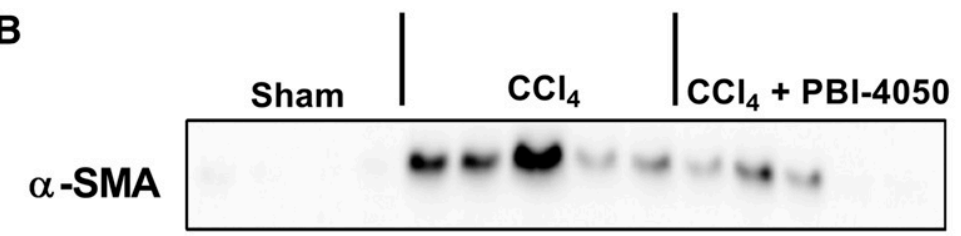

GAPDH

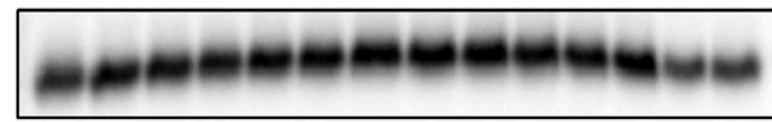

C

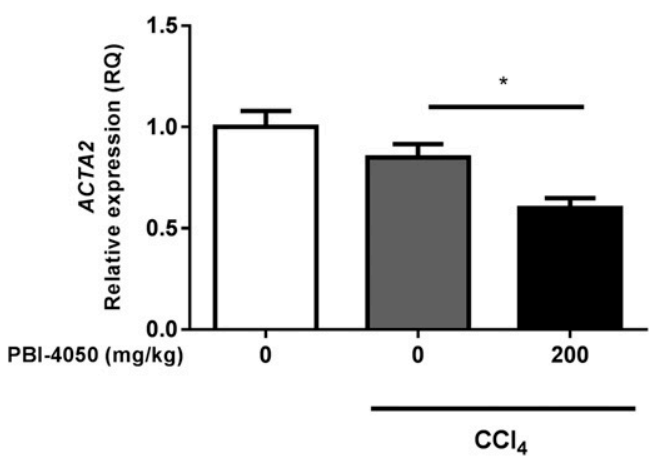

CCl4 + PBI-4050
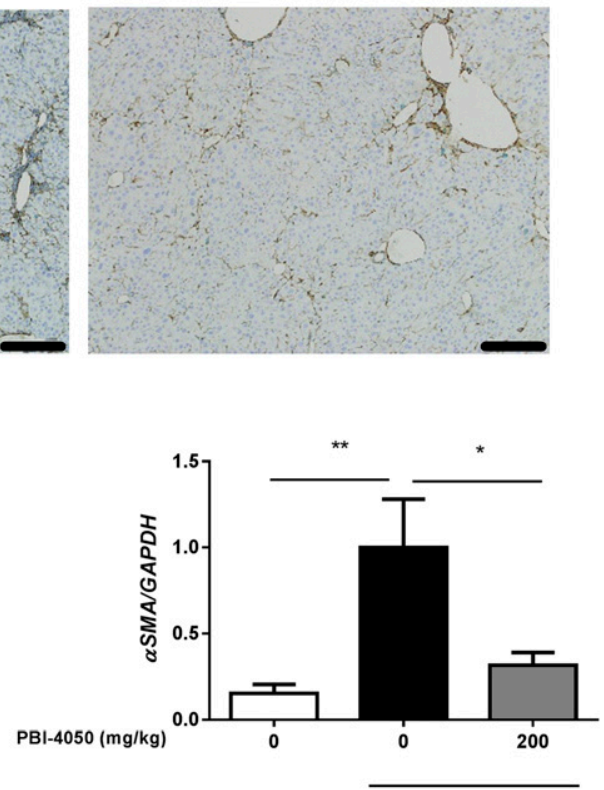

$\mathrm{CCl}_{4}$

Fig. 2. PBI-4050 reduces hepatic $\alpha$-SMA in a $\mathrm{CCl}_{4}$-induced liver fibrosis model. (a) Representative immunohistochemical staining of $\alpha$-SMA in liver sections. (b) Representative Western blot and densitometry analysis of $\alpha$-SMA levels in liver lysates. (c) Hepatic $\alpha$-SMA mRNA expression in liver tissue extracts. Column bar graphs represent the mean \pm S.E.M. (sham, $n=4 ; 200 \mathrm{mg} / \mathrm{kg} \mathrm{CCl}_{4}$ and $200 \mathrm{mg} / \mathrm{kg} \mathrm{CCl}{ }_{4}+\mathrm{PBI}-4050, n=10 \mathrm{each}$ ). $* P<0.05$; $* * P<0.01$, by one-way analysis of variance. Scale bar, $200 \mu \mathrm{m}$.

animals (Fig. 3, A-C). Large amounts of nitric oxide are generated by the proinflammatory marker inducible nitric oxide synthase (iNOS) in many liver diseases, including liver fibrosis, and iNOS inhibition has been considered as a therapeutic strategy in several diseases (Iwakiri, 2015). Indeed, $\mathrm{CCl}_{4}$-treated mice showed higher iNOS expression, which was reduced by PBI-4050 treatment (Fig. 3D). PPAR $\gamma$ downregulation is a well known marker of stellate cell activation (Hazra et al., 2004). Interestingly, PPAR $\gamma$ gene expression decreased by $\mathrm{CCl}_{4}$ treatment was restored to the level of the sham group by PBI-4050 (Fig. 3E). We previously showed that PBI-4050, through binding to GPR40 and GPR84, significantly attenuated fibrosis in various renal fibrosis models (Gagnon et al., 2018). mRNA expression levels of GPR40 and GPR84 in the liver were thus examined. GPR84 gene expression, which was upregulated in $\mathrm{CCl}_{4}$-treated mice, was returned to normal levels by treatment with PBI-4050 (Fig. 3F). No significant level of GPR40 mRNA was detected in the liver samples.

PBI-4050 Attenuates Hepatic Fibrosis Induced by BDL in Rats. To confirm results observed in the $\mathrm{CCl}_{4}$ fibrosis mouse model, we investigated the effect of PBI-4050 in BDL-induced hepatic fibrosis in rats. Histologic analysis revealed that administration of PBI-4050 significantly decreased collagen deposition induced by $\mathrm{BDL}$ in rat livers (Fig. 4, A and B), as seen in the $\mathrm{CCl}_{4}$ mouse model (Fig. 1). Protein levels of $\alpha$-SMA in liver tissues were also analyzed by Western blot, and PBI-4050 treatment considerably decreased $\alpha$-SMA compared with BDL rats (Fig. 3, C and D). Moreover, we also observed a strong upregulation of GPR84 gene expression after BDL (Supplemental Fig. 1).

PBI-4050 Inhibits Cell Proliferation and Cell Cycle Progression in Activated HSCs. HSCs are considered the most prominent cell type involved in liver fibrogenesis (Bataller 
A

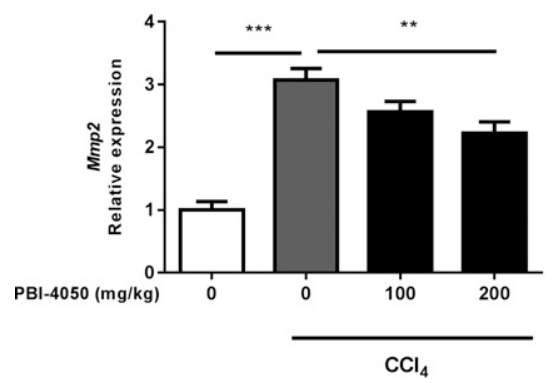

D

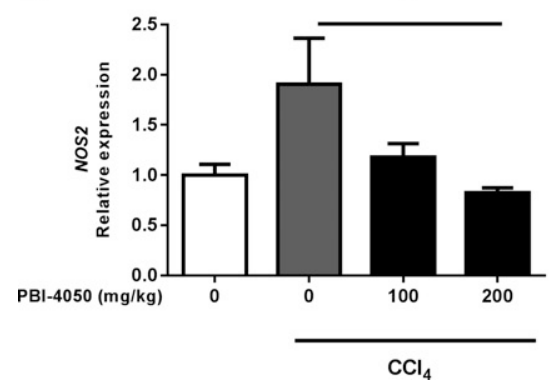

B

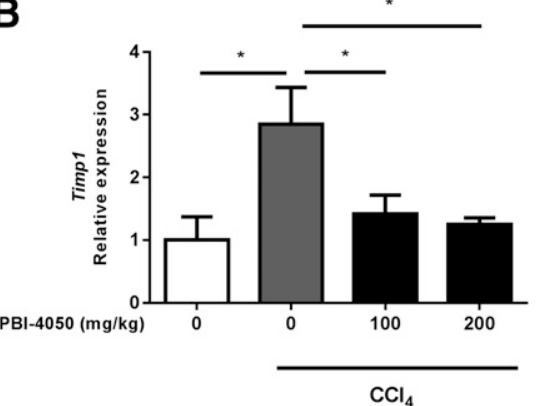

E

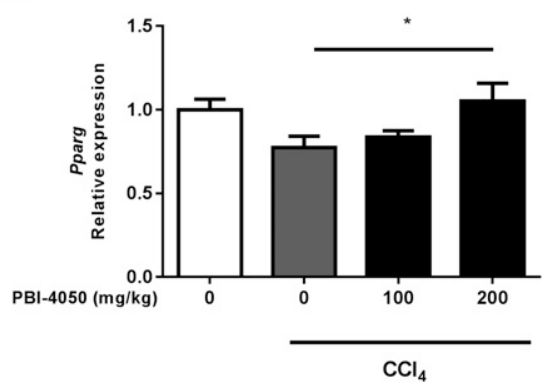

C

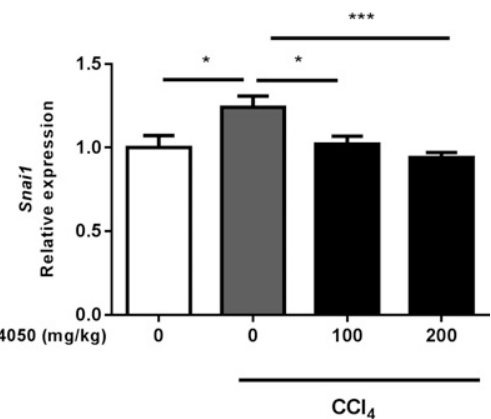

$\mathbf{F}$

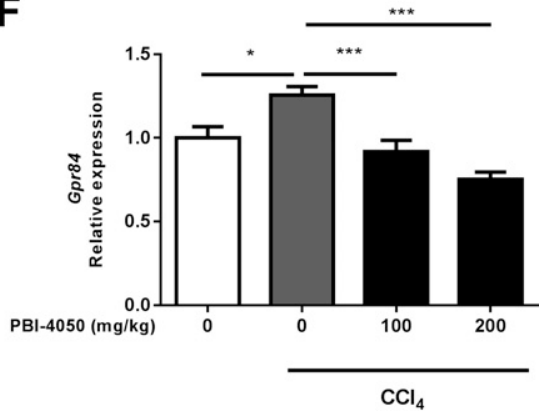

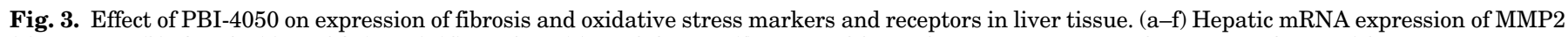

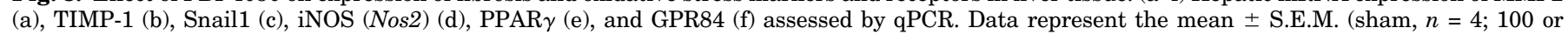
$200 \mathrm{mg} / \mathrm{kg} \mathrm{CCl} \mathrm{CCl}_{4}$ and 100 or $200 \mathrm{mg} / \mathrm{kg} \mathrm{CCl} \mathrm{Cl}_{4}+\mathrm{PBI}-4050, n=10$ each). $* P<0.05$; $* * P<0.01$; ***P<0.001, by one-way analysis of variance.

and Brenner, 2005; Iredale, 2007; Wynn, 2007). Activated HSCs exhibit strong proliferative activity (Puche et al., 2013). In our hands, TGF- $\beta$ increased HSC proliferation by only $10 \%$, as shown in Fig. 5A; this might be due to partial activation of HSCs when they are grown on plastic substrate in tissue culture plates (Gutiérrez-Ruiz and Gómez-Quiroz, 2007).
Nevertheless, 24-hour treatment with $500 \mu \mathrm{M}$ PBI-4050 inhibited TGF- $\beta$-activated HSC proliferation. This decreased cell proliferation was not associated with PBI-4050 cytotoxicity, as proliferation of PBI-4050-treated HSCs was above the time 0 baseline of untreated cells. To confirm these results, cell cycle analysis was performed on HSCs cultured for 24 hours in
A

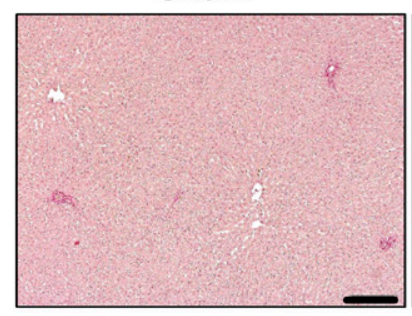

BDL

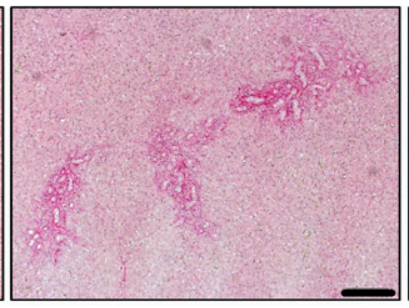

BDL + PBI-4050

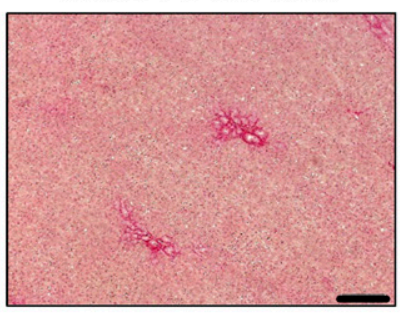

B

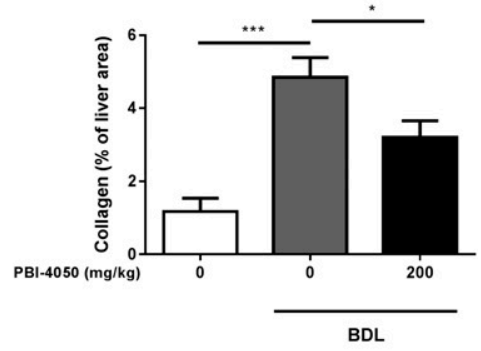

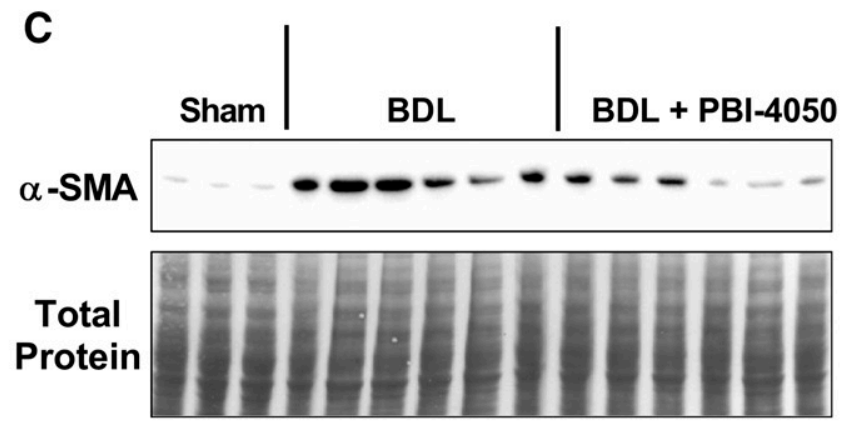

D

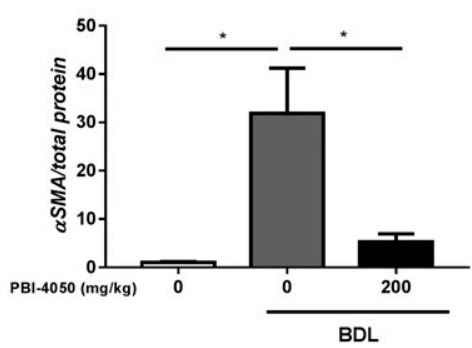

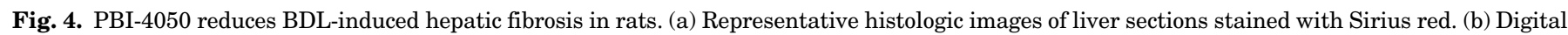

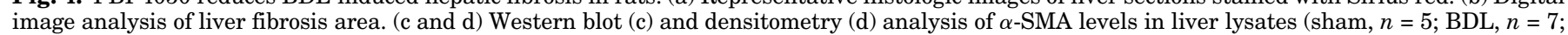
BDL + PBI-4050, $n=6)$. * $p<0.05 ; * P<0.05 ; * * P<0.01 ; * * p<0.001$ by one-way analysis of variance. Scale bar, $200 \mu \mathrm{m}$. 


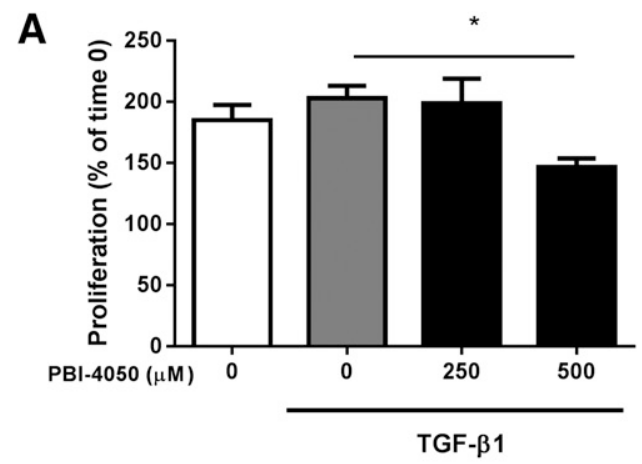

B

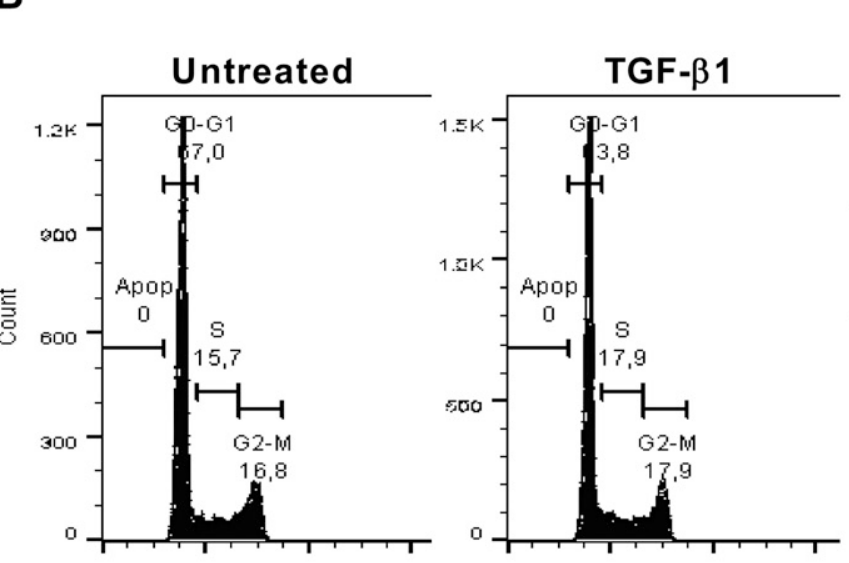

TGF- $\beta 1+$ PBI-4050

TGF- $\beta 1+$ PBI-4050 $(250 \mu \mathrm{M})$

$(500 \mu \mathrm{M})$
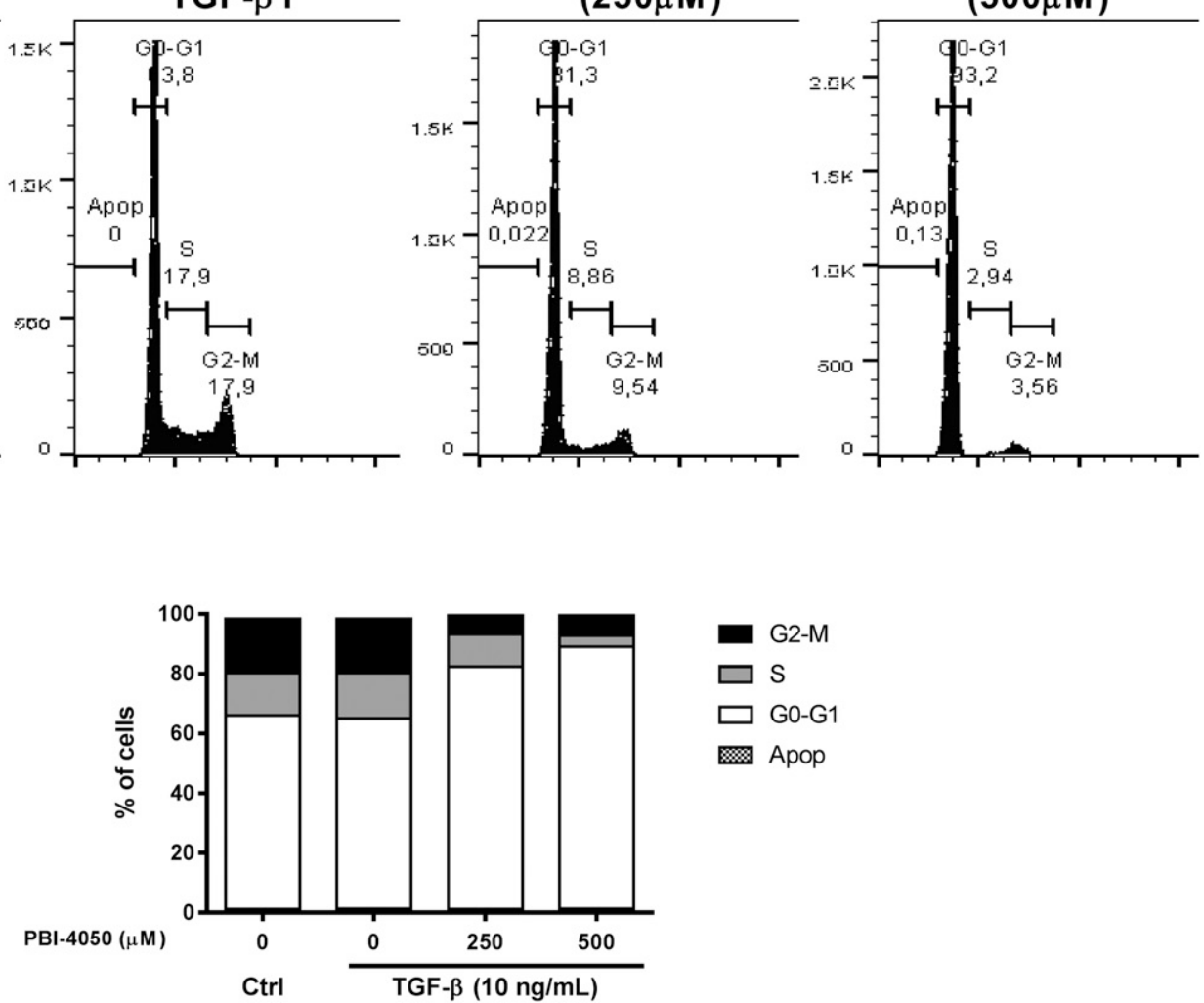

Fig. 5. Antiproliferative effect of PBI-4050 on activated HSCs. (a) Cell proliferation of HSCs treated for 24 hours with $10 \mathrm{ng} / \mathrm{ml}$ TGF- $\beta 1$ and 250 or $500 \mu \mathrm{M}$ PBI- 4050 was assessed by Resazurin reduction at 0 and 24 hours. Results are the mean \pm S.E.M. of three independent experiments. ${ }^{*} p<0.05$; $* P<0.05$; *** $P<0.001$, by one-way analysis of variance. (b) HSCs were treated as described above and the cell cycle was analyzed by flow cytometry. Percentages of cells in the G0/G1, S, G2/M, and apoptosis phases of the cell cycle are shown.

the presence or absence of TGF- $\beta 1$ and PBI-4050. Figure 5B shows that PBI-4050 dose-dependently arrested HSCs at the G0/G1 phase without inducing apoptosis. Similarly, PBI-4050 also blocked HSCs stimulated with the potent proliferative agent PDGF-BB at the G0/G1 phase (Supplemental Fig. 2).

PBI-4050 Regulates the Expression of Fibrosis Markers in Activated HSCs. Stimulation of HSCs with TGF- $\beta$ has been shown to induce a strong increase in the expression of the profibrotic marker CTGF, leading to an increase in $\alpha$-SMA (a myofibroblast marker) (Huang and Brigstock, 2012; Li et al., 2015). Therefore, CTGF and $\alpha$-SMA expression was examined in PBI-4050-treated HSCs. TGF- $\beta$ activation led to a robust increase of $\alpha$-SMA and CTGF, both at the mRNA and protein levels. PBI-4050 treatment significantly and dose-dependently reduced the mRNA expression of these markers (Fig 6A). In addition, protein levels of $\alpha$-SMA and CTGF (Fig. 6, B and C, respectively) were drastically reduced by PBI-4050 treatment, returning to the level detected in untreated cells. Moreover, HSC activation and differentiation has been associated with transcription factor PPAR $\gamma$. Expression of PPAR $\gamma$, detectable in quiescent HSCs, is lacking in activated HSCs and myofibroblasts (Friedman, 2008; Bennett et al., 2017). As shown in Fig. 6A, TGF- $\beta 1$ reduced PPAR $\gamma$ expression in HSCs and PBI-4050 restored its expression in a dose-dependent manner. 
A
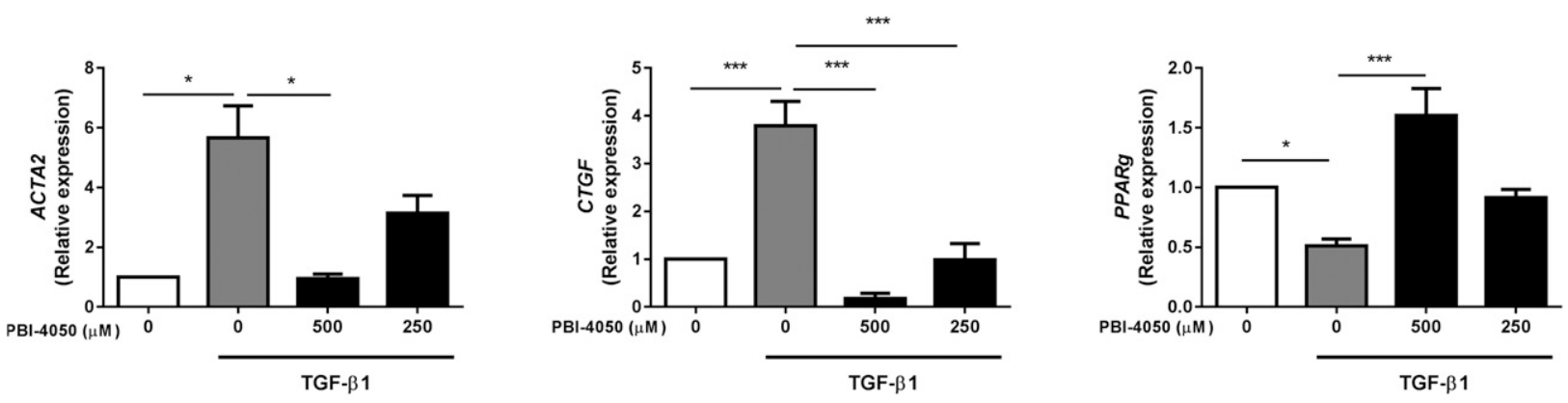

B

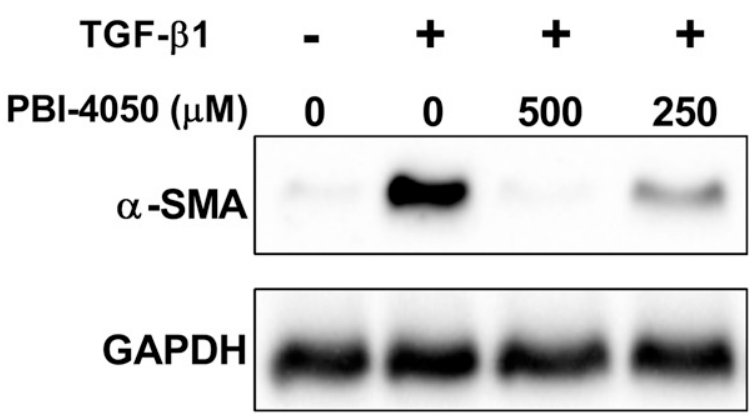

C
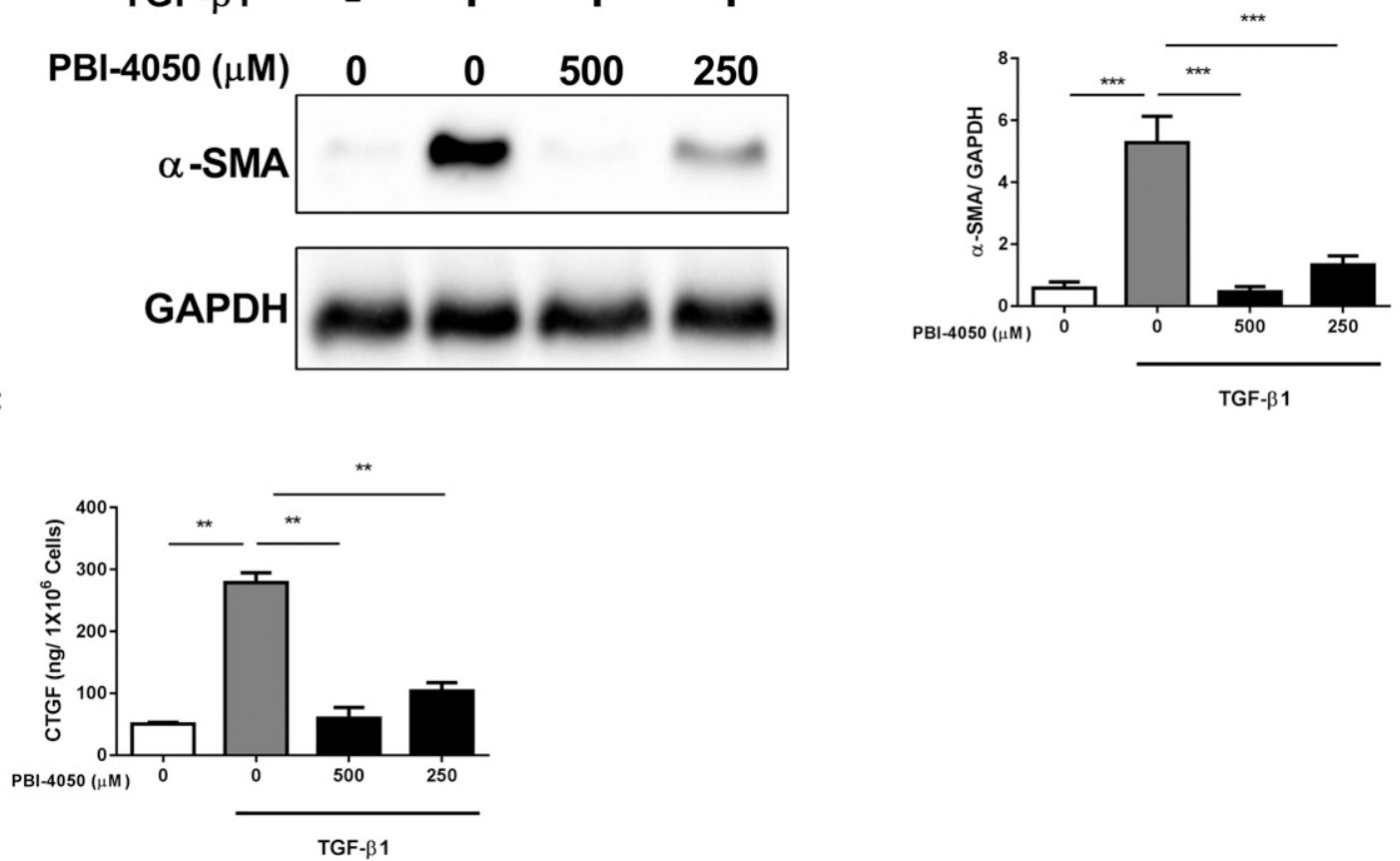

Fig. 6. PBI-4050 abrogates fibrogenic markers in activated HSCs. (a) mRNA expression of activated stellate cell markers $\alpha$-SMA, profibrotic marker CTGF, and PPAR $\gamma$ were determined in TGF- $\beta 1$-stimulated HSCs treated with 250 or $500 \mu \mathrm{M}$ PBI- 4050 for 24 hours. (b) Representative Western blot and densitometry analysis of $\alpha$-SMA protein levels. (c) Secreted protein levels of profibrotic CTGF were measured in the cell supernatant by an enzymelinked immunosorbent assay. Data represent the mean \pm S.E.M. of three independent experiments. ${ }^{*} p<0.05 ; * * p<0.01 ; * * * p<0.001 ; * * P<0.01$; $*_{* *} P<0.001$, by one-way analysis of variance.

PBI-4050 Modulates the LKB1/AMIPK/mTOR Signaling Pathway in Activated HSCs. To further elucidate the mechanism of action of PBI-4050 in vitro, we studied its signaling pathway. GPR40 and GPR84 mRNA were below the detection level in cultured quiescent or TGF- $\beta$-stimulated HSCs, and we thus investigated alternative mechanisms of action in these cells. PBI-4050 did not modulate the TGF- $\beta$-induced canonical Smad2/3 signaling pathway in HSCs (Supplemental Fig. 3). AMPK was previously shown to modulate proliferation and inhibit TGF- $\beta$-induced fibrogenic properties of HSCs (da Silva Morais et al., 2009). Based on our results, we investigated whether the inhibitory effect of PBI-4050 on HSC activation and proliferation could involve phosphorylation of AMPK. As shown in Fig. 7A, treatment with $500 \mu$ M PBI-4050 significantly promoted phosphorylation of AMPK in TGF- $\beta$-activated HSCs. To further elucidate the upstream signaling mechanism of AMPK activation by PBI-4050, phosphorylation of LKB1 (a major upstream kinase in the AMPK cascade) was examined (Fu et al., 2008). Our results show that PBI-4050 treatment increased LKB1 phosphorylation levels (Fig. 7B). Herzig and
Shaw (2018) showed that AMPK activation leads to the modulation of the master regulator of growth, mTOR. Consistent with the literature and AMPK activation by PBI- 4050 treatment, we also demonstrated an inhibition of mTOR phosphorylation (Fig. 7C). Activation of AMPK by LKB1 depends on the intracellular AMP/ATP ratio (Hardie, 2003, 2004) Thus, we next measured the ATP concentration in TGF- $\beta$-activated HSCs treated with PBI-4050. PBI-4050 significantly decreased intracellular ATP at doses of 250 and $500 \mu \mathrm{M}$ (Fig. 7D). Taken together, these results suggest that the inhibitory effect of PBI4050 on HSC activation and proliferation is mediated by reduced intracellular ATP concentrations, LKB1/AMPK activation, and mTOR inhibition.

\section{Discussion}

In this study, we clearly demonstrate the potential therapeutic effect of PBI-4050 in liver fibrosis. It is well known that liver fibrogenesis is accompanied by increased collagen deposition in the perisinusoidal and periportal spaces (Chu et al., 2016). 
A
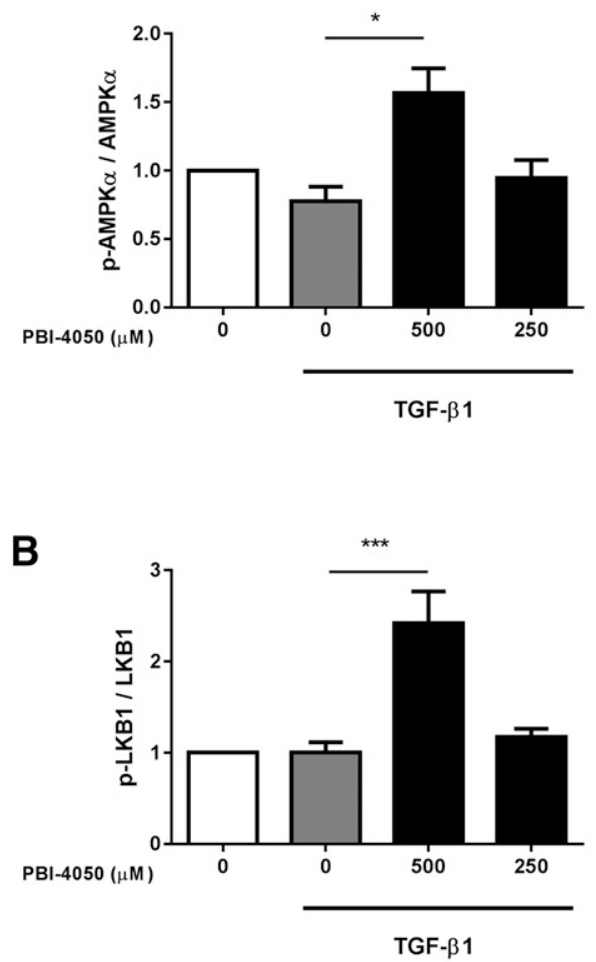

C
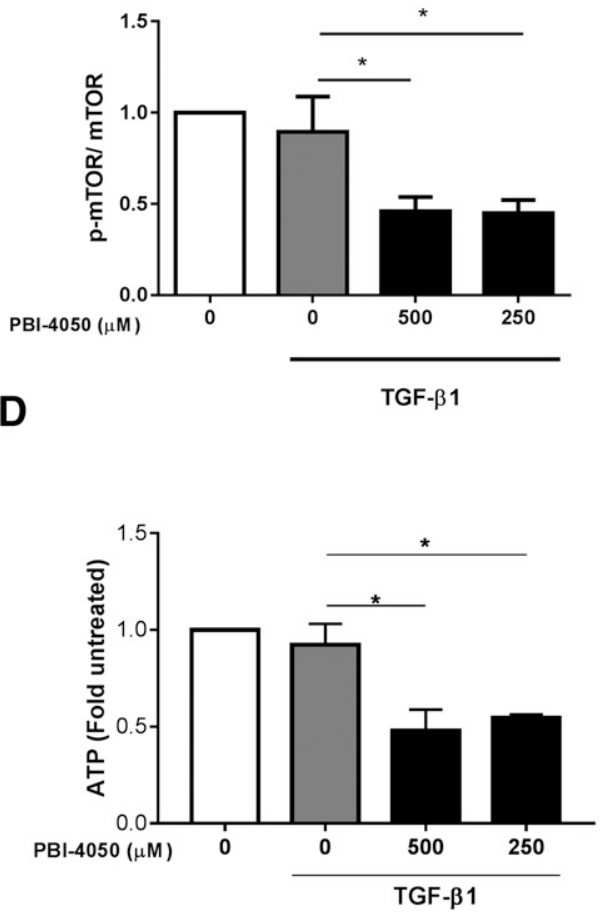

TGF- $\beta 1$

PBI-4050 $(\mu \mathrm{M})$

p-AMPK $\alpha$

AMPK $\alpha$
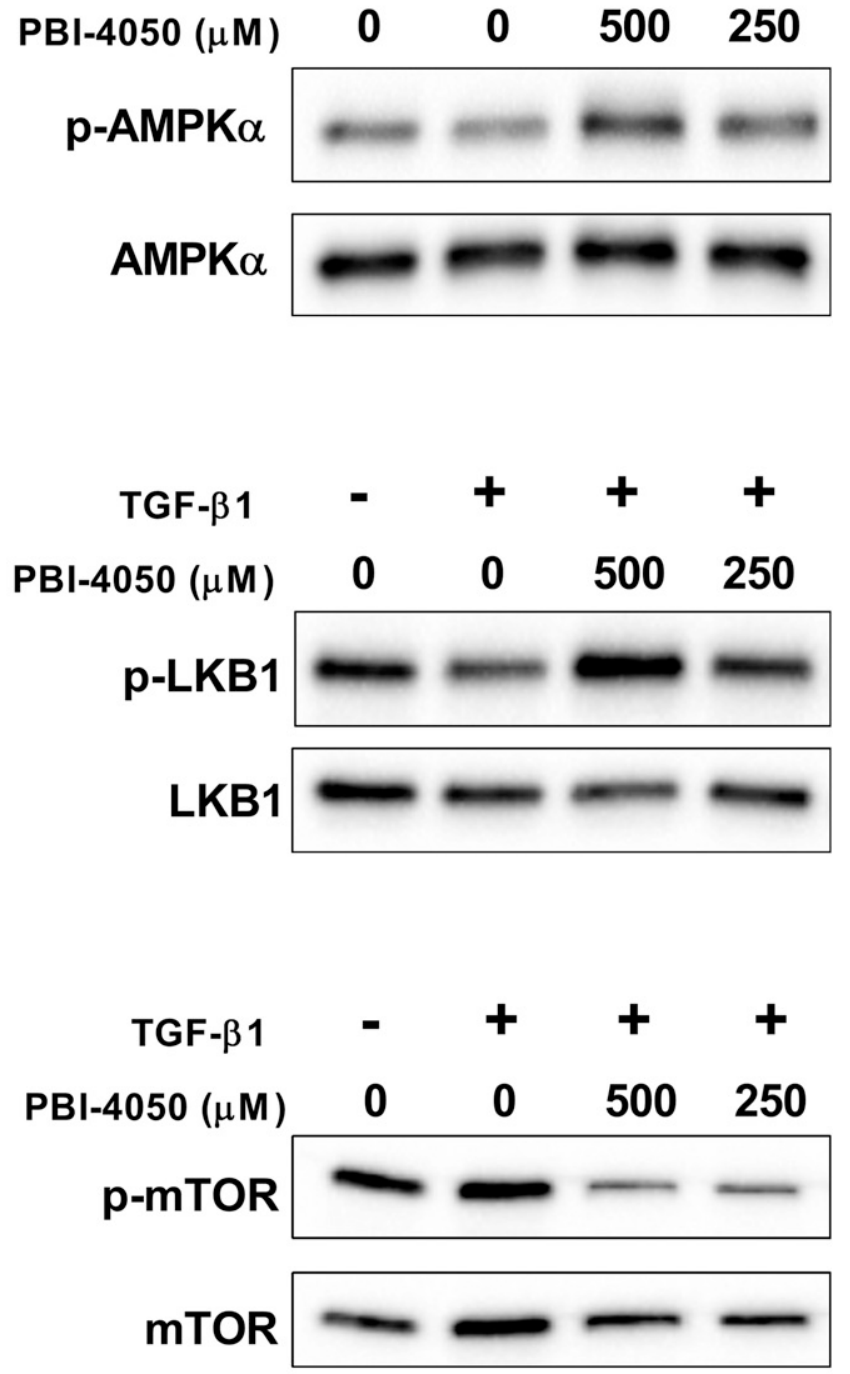

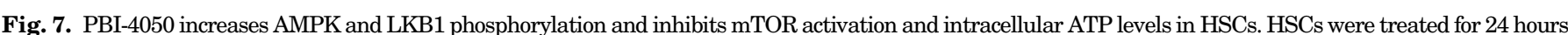

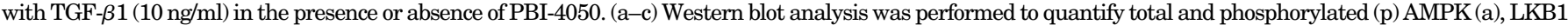

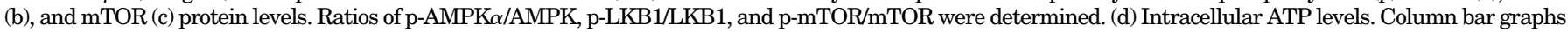

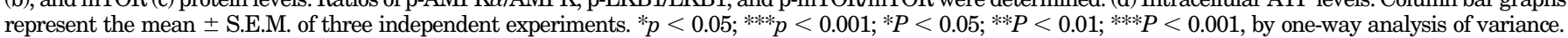

During hepatic fibrogenesis, the TIMP-MMP balance is disturbed and TIMPs are overexpressed, contributing to ECM deposition and the development of fibrosis (Iredale et al., 2013).
Increased expression of TIMP-1 has been observed in both liver tissue and serum of patients with liver disease and in animal models of liver fibrosis (Thiele et al., 2017). PBI-4050 
was efficacious in reducing collagen and other fibrotic markers ( $\alpha$-SMA and CTGF) at the mRNA expression and protein levels in the $\mathrm{CCl}_{4}$-induced hepatotoxicity murine model, and it reduced collagen deposition and $\alpha$-SMA in the BDL rat model. In addition, PBI-4050 induced a marked inhibition of ECM remodeling markers MMP2 and TIMP-1 in $\mathrm{CCl}_{4}$-treated animals as well as negative modulation of the epithelial to mesenchymal transition-related transcription factor Snail1. Expression of the proinflammatory mRNA marker iNOS was also returned to normal in PBI-4050-treated livers. Several natural compounds such as Morin, a plant-derived flavonoid, have been shown to ameliorate liver fibrosis by suppressing iNOS (Dhanasekar and Rasool, 2016). Finally, treatment with PBI-4050 improved liver function, as observed with the reduction of AST activity in mice with $\mathrm{CCl}_{4}$-induced liver injury.

In the liver, HSCs are the major cellular source of ECM. In response to liver injury, hepatocytes, Kupffer cells, and platelets secrete TGF- $\beta$, which activates HSCs in a paracrine fashion (Gressner and Weiskirchen, 2006). Quiescent HSCs undergo a process of trans-differentiation into activated HSCs/myofibroblasts expressing $\alpha$-SMA (Weiler-Normann et al., 2007). In our study, PBI-4050 induced a strong reduction of $\alpha$-SMA expression at both protein and mRNA levels in activated HSCs. These results further strengthen the observed antifibrotic activity of PBI-4050 in preclinical models.

Subsequent signaling analysis in activated HSCs demonstrated that PBI-4050 modulated intracellular ATP and the LKB1/AMPK/mTOR pathway. PBI-4050 displayed more potent effects on lowering intracellular ATP and mTOR phosphorylation than it did on increasing LKB1 and AMPK phosphorylation (only the $500 \mu \mathrm{M}$ dose of PBI-4050 significantly modulated the latter). These results suggest that inhibition of mTOR activation could be a consequence of several pathways that are dependent on PBI-4050 concentration, including activation of the LKB1/AMPK pathway and decreased direct binding of ATP to mTOR. Indeed, mTOR has an ATP binding pocket and is an ATP sensor (Dennis et al., 2001; Yang et al., 2013). Previous studies also showed that phosphorylation of mTOR at Ser2448, measured in this study, can be regulated as a feedback signal to mTOR from its major downstream target, p70S6 kinase (Chiang and Abraham, 2005).

Interestingly, the inhibition of HSC proliferation through a G0/G1 cell cycle arrest induced by PBI- 4050 corroborates with previous work showing that activation of AMPK could suppress HSC proliferation (Gressner and Weiskirchen, 2006). Previous studies have also reported that AMPK stimulation negatively controls the expression of $\alpha$-SMA and other markers of fibrosis in HSCs (da Silva Morais et al., 2009; Lee et al., 2016), which is in agreement with our results in PBI-4050-treated HSCs. There is increasing evidence showing a beneficial role of AMPK activation in reducing hepatic fibrosis, improving liver function, and lowering hepatocytotoxicity (Liang et al., 2017). In addition, several novel drug candidates for the treatment of hepatic fibrosis, including metformin, betulin, berberine, cucurbitacin $\mathrm{E}$, and curcumin, have been shown to act via increased AMPK signaling (Xu et al., 2003; Fu et al., 2008; Yang et al., 2015; Wu et al., 2016; Liang et al., 2017). Moreover, AMPK signaling is known to negatively regulate mTOR, an atypical serine/threonine kinase shown to play an important role in the regulation of cell growth, differentiation, migration, and survival through transcription factors $\mathrm{S} 6 \mathrm{~K} 1,4 \mathrm{EBP} 1$, and PPAR $\gamma$. mTOR inhibitors have become a target to suppress the activation of HSCs and liver fibrosis (Zhai et al., 2015).

Studies show that PPAR $\gamma$ is a critical transcription factor involved in the inhibition of HSC activation (Hazra et al., 2004; Zhai et al., 2015). Interestingly, PBI-4050 restored PPAR $\gamma$ expression, which was downregulated in TGF- $\beta$-activated HSCs and in $\mathrm{CCl}_{4}$ liver extracts. Upregulation of PPAR $\gamma$ was also

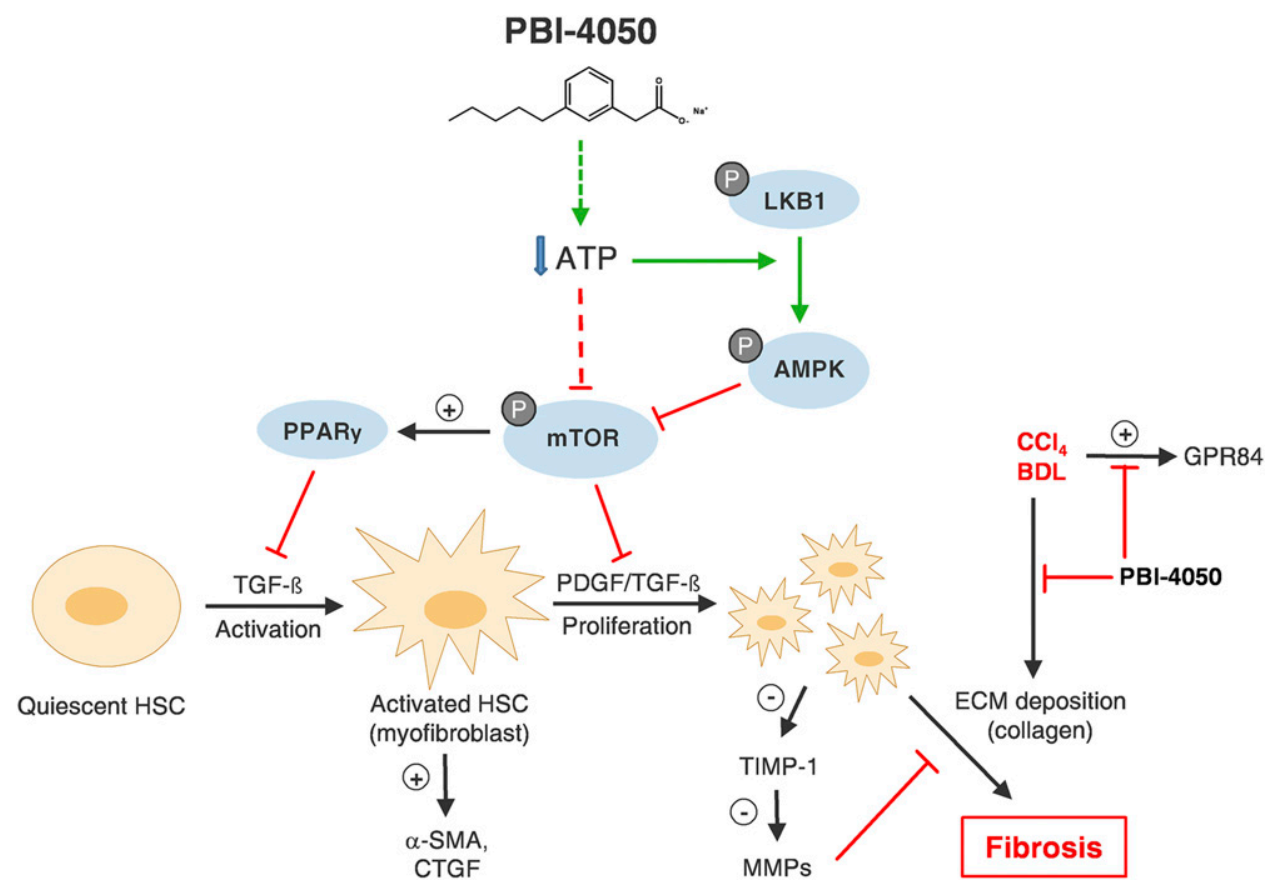

Fig. 8. A schematic representation showing the protective effect of PBI-4050 on hepatic fibrosis. PBI-4050 decreases intracellular ATP levels and activates LKB1, one of the upstream kinases phosphorylating AMPK. In turn, activated AMPK and low ATP levels can inhibit the cell growth master regulator $\mathrm{mTOR}$ and thereby restore PPAR $\gamma$ expression, leading to inhibition of HSC activation and proliferation. Consequently, fibrotic and remodeling markers are decreased by PBI-4050, resulting in improvement of hepatic fibrosis. 
associated with increased phospho-AMPK and decreased phospho-mTOR (Zhong et al., 2018). Additional studies are required to further elucidate the mechanism of action of PBI-4050 in TGF- $\beta$-activated HSCs, especially by investigating downstream effectors of mTOR that control cell growth and protein synthesis as well as autophagy; however, PBI-4050 did not have any effect on canonical TGF- $\beta$ signaling through Smad2/3 phosphorylation in HSCs (Supplemental Fig. 3).

Furthermore, although GPR40 and GPR84 were not expressed in cultured quiescent or TGF- $\beta$-stimulated HSCs, other stimuli such as tumor necrosis factor- $\alpha$ and lipopolysaccharide (which could be found in an in vivo pathologic context) induced mRNA expression of GPR84 in HSCs (Supplemental Fig. 4). Our previous work showed an upregulation of renal GPR84 expression and a profibrotic role of GPR84 in kidney fibrosis models (Gagnon et al., 2018). Increased GPR84 expression was also observed in the $\mathrm{CCl}_{4}$ model and may be linked to the increase in fibrosis, as PBI-4050 treatment decreased both GPR84 expression and fibrosis in this model. Further work is required to determine the precise role of GPR84 in liver fibrogenesis.

Figure 8 summarizes the preliminary novel signaling pathway of PBI-4050 extracted from the data obtained in HSCs and the $\mathrm{CCl}_{4}$-induced liver fibrosis model. The antifibrotic and antiproliferative activity of PBI-4050 on activated HSCs seemed to be mediated through the modulation of intracellular ATP and the LKB1/AMPK/mTOR/PPAR $\gamma$ signaling axis, resulting in regulation of hepatic ECM deposition and remodeling and in decreased liver fibrosis.

\section{Authorship Contributions}

Participated in research design: Grouix, Sarra-Bournet, Laurin, L. Gagnon.

Conducted experiments: Sarra-Bournet, Simard, Hince, Geerts, Blais, Gervais, Laverdure, Felton, Richard, Ouboudinar, W. Gagnon.

Performed data analysis: Grouix, Sarra-Bournet, Simard, Hince, Geerts, Blais, Gervais, Laverdure, Leblond.

Wrote or contributed to the writing of the manuscript: Grouix, Sarra-Bournet, Leduc, Simard, L. Gagnon.

\section{References}

Bataller R and Brenner DA (2005) Liver fibrosis. J Clin Invest 115:209-218.

Bennett RG, Simpson RL, and Hamel FG (2017) Serelaxin increases the antifibrotic action of rosiglitazone in a model of hepatic fibrosis. World $J$ Gastroenterol 23 $3999-4006$.

Biecker E, De Gottardi A, Neef M, Unternährer M, Schneider V, Ledermann M, Sägesser H, Shaw S, and Reichen J (2005) Long-term treatment of bile duct-ligated rats with rapamycin (sirolimus) significantly attenuates liver fibrosis: analysis of the underlying mechanisms. J Pharmacol Exp Ther 313:952-961.

Briscoe CP, Tadayyon M, Andrews JL, Benson WG, Chambers JK, Eilert MM, Ellis C, Elshourbagy NA, Goetz AS, Minnick DT, et al. (2003) The orphan G proteincoupled receptor GPR40 is activated by medium and long chain fatty acids. $J$ Biol Chem 278:11303-11311.

Chiang GG and Abraham RT (2005) Phosphorylation of mammalian target of rapamycin (mTOR) at Ser-2448 is mediated by p70S6 kinase. J Biol Chem 280 $25485-25490$.

Chu X, Wang H, Jiang YM, Zhang YY, Bao YF, Zhang X, Zhang JP, Guo H, Yang F, Luan YC, et al. (2016) Ameliorative effects of tannic acid on carbon tetrachlorideinduced liver fibrosis in vivo and in vitro. J Pharmacol Sci 130:15-23.

da Silva Morais A, Abarca-Quinones J, Guigas B, Viollet B, Stärkel P, Horsmans Y, and Leclercq IA (2009) Development of hepatic fibrosis occurs normally in AMPKdeficient mice. Clin Sci (Lond) 118:411-420.

Dennis PB, Jaeschke A, Saitoh M, Fowler B, Kozma SC, and Thomas G (2001) Mammalian TOR: a homeostatic ATP sensor. Science 294:1102-1105.

Dhanasekar C and Rasool M (2016) Morin, a dietary bioflavonol suppresses monosodium urate crystal-induced inflammation in an animal model of acute gouty arthritis with reference to NLRP3 inflammasome, hypo-xanthine phospho-ribosyl transferase, and inflammatory mediators. Eur $J$ Pharmacol 786:116-127.

Fan K, Wu K, Lin L, Ge P, Dai J, He X, Hu K, and Zhang L (2017) Metformin mitigates carbon tetrachloride-induced TGF- $31 /$ Smad3 signaling and liver fibrosis in mice. Biomed Pharmacother 90:421-426.
Friedman SL (2000) Molecular regulation of hepatic fibrosis, an integrated cellular response to tissue injury. J Biol Chem 275:2247-2250.

Friedman SL (2008) Hepatic stellate cells: protean, multifunctional, and enigmatic cells of the liver. Physiol Rev 88:125-172.

Fu Y, Zheng S, Lin J, Ryerse J, and Chen A (2008) Curcumin protects the rat liver from CCl4-caused injury and fibrogenesis by attenuating oxidative stress and suppressing inflammation. Mol Pharmacol 73:399-409.

Gagnon L, Leduc M, Thibodeau JF, Zhang MZ, Grouix B, Sarra-Bournet F, Gagnon W, Hince K, Tremblay M, Geerts L, et al. (2018) A newly discovered antifibrotic pathway regulated by two fatty acid receptors: GPR40 and GPR84. Am J Pathol 188:1132-1148.

Gressner AM and Weiskirchen R (2006) Modern pathogenetic concepts of liver fibrosis suggest stellate cells and TGF-beta as major players and therapeutic targets. J Cell Mol Med 10:76-99.

Gutiérrez-Ruiz MC and Gómez-Quiroz LE (2007) Liver fibrosis: searching for cell model answers. Liver Int 27:434-439.

Hardie DG (2003) Minireview: the AMP-activated protein kinase cascade: the key sensor of cellular energy status. Endocrinology 144:5179-5183.

Hardie DG (2004) The AMP-activated protein kinase pathway-new players upstream and downstream. J Cell Sci 117:5479-5487.

Hazra S, Xiong S, Wang J, Rippe RA, Krishna V, Chatterjee K, and Tsukamoto H (2004) Peroxisome proliferator-activated receptor gamma induces a phenotypic switch from activated to quiescent hepatic stellate cells. J Biol Chem 279: $11392-11401$.

Henderson NC and Iredale JP (2007) Liver fibrosis: cellular mechanisms of progression and resolution. Clin Sci (Lond) 112:265-280.

Herzig S and Shaw RJ (2018) AMPK: guardian of metabolism and mitochondrial homeostasis. Nat Rev Mol Cell Biol 19:121-135.

Huang G and Brigstock DR (2012) Regulation of hepatic stellate cells by connective tissue growth factor. Front Biosci 17:2495-2507.

Iredale JP (2007) Models of liver fibrosis: exploring the dynamic nature of inflammation and repair in a solid organ. J Clin Invest 117:539-548.

Iredale JP, Thompson A, and Henderson NC (2013) Extracellular matrix degradation in liver fibrosis: biochemistry and regulation. Biochim Biophys Acta 1832 $876-883$

Iwakiri Y (2015) Nitric oxide in liver fibrosis: the role of inducible nitric oxide synthase. Clin Mol Hepatol 21:319-325.

Kumar P, Smith T, Rahman K, Thorn NE, and Anania FA (2014) Adiponectin agonist ADP355 attenuates CCl4-induced liver fibrosis in mice. PLoS One 9: e110405.

Kweon SM, Chi F, Higashiyama R, Lai K, and Tsukamoto H (2016) Wnt pathway stabilizes MeCP2 protein to repress PPAR- $\gamma$ in activation of hepatic stellate cells. PLoS One 11:e0156111.

Leclerc GM, Leclerc GJ, Fu G, and Barredo JC (2010) AMPK-induced activation of Akt by AICAR is mediated by IGF-1R dependent and independent mechanisms in acute lymphoblastic leukemia. J Mol Signal 5:15.

Lee HS, Shin HS, Choi J, Bae SJ, Wee HJ, Son T, Seo JH, Park JH, Kim SW, and Kim KW (2016) AMP-activated protein kinase activator, HL156A reduces thioacetamide-induced liver fibrosis in mice and inhibits the activation of cultured hepatic stellate cells and macrophages. Int J Oncol 49:1407-1414.

Li J, Dong N, Cheng S, Li X, Wang W, and Xiang Y (2015) Tetramethylpyrazine inhibits CTGF and Smad2/3 expression and proliferation of hepatic stellate cells. Biotechnol Biotechnol Equip 29:124-131.

Li J, Pan Y, Kan M, Xiao X, Wang Y, Guan F, Zhang X, and Chen L (2014) Hepatoprotective effects of berberine on liver fibrosis via activation of AMP-activated protein kinase. Life Sci 98:24-30.

Liang Z, Li T, Jiang S, Xu J, Di W, Yang Z, Hu W, and Yang Y (2017) AMPK: a novel target for treating hepatic fibrosis. Oncotarget 8:62780-62792.

Lim JY, Oh MA, Kim WH, Sohn HY, and Park SI (2012) AMP-activated protein kinase inhibits TGF- $\beta$-induced fibrogenic responses of hepatic stellate cells by targeting transcriptional coactivator p300. J Cell Physiol 227:1081-1089.

Puche JE, Saiman Y, and Friedman SL (2013) Hepatic stellate cells and liver fibrosis. Compr Physiol 3:1473-1492.

Schuppan D and Kim YO (2013) Evolving therapies for liver fibrosis. J Clin Invest 123:1887-1901.

Thiele ND, Wirth JW, Steins D, Koop AC, Ittrich H, Lohse AW, and Kluwe J (2017) TIMP-1 is upregulated, but not essential in hepatic fibrogenesis and carcinogenesis in mice. Sci Rep 7:714.

Tripathi DM, Erice E, Lafoz E, García-Calderó H, Sarin SK, Bosch J, Gracia-Sancho J, and García-Pagán JC (2015) Metformin reduces hepatic resistance and portal pressure in cirrhotic rats. Am J Physiol Gastrointest Liver Physiol 309: G301-G309.

Wang J, Wu X, Simonavicius N, Tian H, and Ling L (2006) Medium-chain fatty acids as ligands for orphan G protein-coupled receptor GPR84. J Biol Chem 281: 34457-34464.

Wang N, Xu Q, Tan HY, Hong M, Li S, Yuen MF, and Feng Y (2016) Berberine inhibition of fibrogenesis in a rat model of liver fibrosis and in hepatic stellate cells. Evid Based Complement Alternat Med 2016:8762345.

Weiler-Normann C, Herkel J, and Lohse AW (2007) Mouse models of liver fibrosis. $Z$ Gastroenterol 45:43-50.

Wu YL, Zhang YJ, Yao YL, Li ZM, Han X, Lian LH, Zhao YQ, and Nan JX (2016) Cucurbitacin $\mathrm{E}$ ameliorates hepatic fibrosis in vivo and in vitro through activation of AMPK and blocking mTOR-dependent signaling pathway. Toxicol Lett 258: $147-158$.

Wynn TA (2007) Common and unique mechanisms regulate fibrosis in various fibroproliferative diseases. J Clin Invest 117:524-529.

$\mathrm{Xu} \mathrm{J}, \mathrm{Fu} \mathrm{Y}$, and Chen A (2003) Activation of peroxisome proliferator-activated receptor-gamma contributes to the inhibitory effects of curcumin on rat hepatic stellate cell growth. Am J Physiol Gastrointest Liver Physiol 285: G20-G30. 
Yang H, Rudge DG, Koos JD, Vaidialingam B, Yang HJ, and Pavletich NP (2013) mTOR kinase structure, mechanism and regulation. Nature 497: $217-223$.

Yang Y, Zhao Z, Liu Y, Kang X, Zhang H, and Meng M (2015) Suppression of oxidative stress and improvement of liver functions in mice by ursolic acid via LKB1-AMPactivated protein kinase signaling. J Gastroenterol Hepatol 30:609-618.

Zhai X, Qiao H, Guan W, Li Z, Cheng Y, Jia X, and Zhou Y (2015) Curcumin regulates peroxisome proliferator-activated receptor- $\gamma$ coactivator- $1 \alpha$ expression by AMPK pathway in hepatic stellate cells in vitro. Eur J Pharmacol $\mathbf{7 4 6}$ $56-62$.
Zhong J, Gong W, Chen J, Qing Y, Wu S, Li H, Huang C, Chen Y, Wang Y, Xu Z, et al. (2018) Micheliolide alleviates hepatic steatosis in $\mathrm{db} / \mathrm{db}$ mice by inhibiting inflammation and promoting autophagy via PPAR- $\gamma$-mediated NF-kB and AMPK/mTOR signaling. Int Immunopharmacol 59:197-208.

Address correspondence to: Dr. Lyne Gagnon, Prometic BioSciences Inc., 500 Cartier Ouest Blvd., Suite 150, Laval, QC H7V 5B7, Canada. E-mail: l.gagnon@prometic.com 